\title{
Assessment of cardiometabolic risk factors among adolescent survivors of childhood cancer
}

\author{
Gonzalo Agüero, M.D., ${ }^{a}$ and Carlos Sanz, M.D. ${ }^{b}$
}

\begin{abstract}
Introduction. Survivors of childhood cancer have an increased risk of developing cardiovascular and metabolic disease as adults, secondary to cancer treatment. During adolescence, habits are developed which have a negative impact on the development of these conditions.

Objectives. To estimate the prevalence of cardiometabolic risk factors among adolescent survivors of childhood cancer (ASCC) and compare them to healthy adolescents.

Population and methods. Cross-sectional, analytical study. Location: Department of Adolescence, Hospital Elizalde, Buenos Aires. Subjects included were 61 ASCC and 138 healthy adolescents. Age: $15 \pm 3$ years old, range: 1021 years old. The level of physical activity in the past 30 days, adding salt to foods, weekly consumption of fruit and vegetables, tobacco use, alcohol use, body mass index, and waist circumference were analyzed.

Results. ASCC were significantly more obese (19.7\% versus $7.2 \%, p=0.019$, odds ratio 3.01 ) and had a larger waist circumference $(19.7 \%$ versus $8 \%, p=0.017$, odds ratio 2.82 ) than healthy adolescents. In addition, they did not eat vegetables more frequently $(26.2 \%$ versus $13 \%$, $p=0.017)$. No statistically significant differences were found in terms of prevalence for the other risk factors: usually adding salt to foods ( $55.7 \%)$, lack of fruit consumption (32.8\%), low level of physical activity $(60.7 \%)$, tobacco use $(4.9 \%)$, and alcohol use (39\%).

Conclusions. ASCC had a higher risk for obesity and a larger waist circumference; in addition, they ate less vegetables than adolescents without a history of cancer. The prevalence of the remaining factors for cardiometabolic risk was similar.

Key words: adolescent, neoplasia, risk, tobacco use, obesity.
\end{abstract}

http:/ /dx.doi.org/10.5546/aap.2015.eng.119

\section{INTRODUCTION}

As a result of advances in childhood cancer treatment, the survival rate has undergone a significant increase and has reached $80 \% 5$ years after diagnosis in developed countries. ${ }^{1}$

However, chemotherapy and radiotherapy cause organ damage which is not clinically evident until several years later. Thus, many childhood cancer survivors will have major cardiovascular morbidity and mortality during their adulthood ${ }^{2-4}$ and will develop obesity, metabolic syndrome, accelerated atherosclerosis and early cardiovascular events. 5,6 These events, together with an inactive lifestyle ${ }^{9,10}$ and tobacco use, ${ }^{11}$ are secondary to cancer treatment complications (anthracycline chemotherapy regimen, ${ }^{7}$ thoracic and cranial radiotherapy). ${ }^{8,9}$

Although cancer survivors have a higher risk for late cardiometabolic events, they are mostly sedentary, frequently use tobacco and alcohol, ${ }^{12-14}$ even since adolescence, ${ }^{15}$ and do not attend periodic medical check-ups. ${ }^{16}$

In Argentina, the annual incidence of childhood cancer is 124/1 000000 in children younger than 15 years old, with an average survival of $65 \% .{ }^{17,18}$

During adolescence, many childhood cancer survivors, and their healthy peers, lead a potentially detrimental lifestyle, such as being sedentary or using tobacco and alcohol.

Our objective was to estimate the prevalence of cardiometabolic risk factors in a group of ASCC and compare it to that of healthy adolescents.

\section{POPULATION, MATERIALS AND METHODS}

Cross-sectional, analytical study conducted at the Department of Adolescence of Hospital Elizalde (HGNPE, Buenos Aires) between July 2011 and May 2012.

\section{Inclusion criteria}

- Adolescent survivors of childhood cancer (ASCC) aged 10 to 21 years old, diagnosed with cancer between January $1^{\text {st }}, 2000$ and December $31^{\text {st }}, 2006$ at the HGNPE, with a survival of $\geq 5$ years after diagnosis. 
- Adolescents aged 10 to 21 years old, with no personal history of cancer, who attended a healthcare check-up at the HGNPE. One in every five adolescents who attended a health check-up was invited to participate.

Adolescents with motor skill disorders or lung, liver or infectious conditions (chronic or acute) were excluded.

The same health care professional interviewed each adolescent.

\section{Study outcome measures}

1. Level of physical activity in the past month Intense or vigorous physical activity (VPA): equivalent to jogging that makes you sweat and feel "breathless." Moderate physical activity (MPA): equivalent to a brisk walking that makes you feel overheated and mildly "breathless."

The level of PA was considered low if the subject reported no physical activity or a lower than moderate level. Moderate level of PA: any of the following: a) 3 or more days a week of VPA during, at least, 20 minutes; b) 5 or more days of MPA during, at least, 30 minutes. High level of PA: any of the following: a) 3 or more days a week of VPA during, at least, 1 hour; b) 5 or more days of MPA during, at least, 1 hour.

\section{Nutrition}

Adding salt to foods (always, rarely or never). Weekly consumption of fruits and vegetables: a. adequate consumption: 5 or more times a week;

b.low consumption: 4 or less times a week;

c.no consumption: no fruits and/or vegetables.

3. Anthropometric data

Body mass index and waist circumference (WC). WC was measured at the upper edge of the right iliac crest at the end of an unforced expiration (tables by Fernández, et al.). Percentile tables adjusted for sex and age were used. ${ }^{19,20}$

4. Tobacco use

Age at initiation, smoking pattern (nonsmoker, smoker, former smoker) and exposure to tobacco smoke at home in the past 12 months.

Definitions: Non-smoker: someone who never smoked. Present smoker: someone who has smoked in the past 30 days and who has smoked 100 or more cigarettes in his/her life. Former smoker: someone who used to smoke but has not smoked in the past month.

\section{Alcohol use}

Age at initiation, type of drink, consumption pattern (present alcohol user, someone who has ever used alcohol, non drinker). Occasional excessive alcohol use and alcohol abuse were assessed for present alcohol users by counting the number of alcoholic drinks per week and/or weekend. The CRAFFT questionnaire was also used, which is a validated tool for substance abuse screening among adolescents. In this article, the CRAFFT questionnaire was used to assess alcohol abuse.

Definitions: Drink: equivalent to the same amount of alcohol (approximately 12 grams) for each beverage, such as: 1 can of beer, 1 glass of wine, 1 "strong" drink (whisky, vodka, fernet, etc.). Non drinker: someone who has never drunk alcohol.

Ever used alcohol: someone who has ever drunk, at least one or two sips of alcohol.

Present alcohol user: someone who has drunk alcohol in the past 30 days.

Alcohol abuse (at-risk drinking): a female who drinks an average 7 beverages per week or a male who drinks an average 14 beverages per week.

Occasional excessive alcohol use (OEAU): someone who drinks 5 or more alcoholic beverages on one occasion.

\section{Ethical considerations}

The study was approved by the HGNPE Research and Teaching Committee and Ethics Committee. An informed consent was obtained from all participants and adult caregivers.

\section{Statistical analysis}

For qualitative outcome measures, frequency and percentage values were used, together with their corresponding 95\% confidence interval (CI), and compared using the chi-square test. For dichotomous outcome measures, if frequency was lower than 5, Fisher's exact test was used. For quantitative outcome measures, average, standard deviation, minimum and maximum values were estimated and compared using Student's $t$ test for independent samples and ANOVA.

If outcome measures did not follow a normal distribution, variances were not homogenous and/or showed a high symmetry, non-parametric statistical tests were used (Mann-Whitney, Kruskal- Wallis). Data were processed using the Epidat 3.1 and SPSS 11.5 software.

Among study factors, tobacco use was the least 
frequent one, with a $20 \%$ estimated prevalence for ASCC. Assuming a $\pm 5 \%$ accuracy, the sample size was estimated at 83 patients. This allows to identify differences of, at least, $17 \%$ in smoking habit when compared to the healthy adolescent group, with a $95 \% \mathrm{CI}$ and an $80 \%$ power $(\alpha=0.05$ and $\beta=0.2)$. Case/control ratio: $1 / 2$.

\section{RESULTS}

The Argentine Hospital Oncopediatric Registry (Registro Oncopediátrico Hospitalario Argentino, ROHA) was used to look for patients diagnosed with childhood cancer at the HGNPE between January 1st, 2000 and December 31st, 2006. One hundred and twenty-five adolescents who could potentially be included were found.

Inclusion was sequential, as patients were contacted on the telephone or seen at the hospital. Fifteen patients refused to participate, 2 had died, and it was not possible to contact 47 because their data were out of date.

Sixty-one ASCC were included, accounting for $73 \%$ of the sample size, together with 138 healthy adolescents, for a total sample made up of 199 adolescents.

There were more females in the healthy adolescent group $(65.9 \%$ versus $50.8 \%, p=0.043)$. There were no significant differences between the ASCC and the healthy adolescent groups in relation to the other factors: age $(16 \pm 4$ years old versus $15 \pm 2$ years old, $p=0.068)$, nationality (Argentine: $93.4 \%$ versus $90.6 \%, p=0.505$ ), current place of residence (Greater Buenos Aires: 88.5\% versus $82.6 \%, p=0.390)$.

ASCC had been diagnosed with leukemia $(49 \%)$, lymphoma $(17 \%)$, germ cell tumor $(13 \%)$, kidney tumor $(8 \%)$, sarcoma $(6 \%)$, peripheral nervous system (NS) tumor (3\%), central NS tumor $(2 \%)$, and carcinoma $(2 \%)$.

\section{Obesity and waist circumference}

ASCC included 5 girls and 7 boys who were obese. They had been diagnosed with leukemia (10 cases), lymphoma (1 case) and Wilms tumor (1 case). ASCC had a higher proportion of obesity $(19.7 \%$ versus $7.2 \%, p=0.019)$, odds ratio $=3.13$ (95\% CI: 1.27-7.72). They also had a higher proportion of large WC or $\geq 90$ th percentile $(19.7 \%$ versus $8 \%, p=0.017)$, odds ratio $=2.82(95 \% \mathrm{CI}$ : 1.17-6.83).

\section{Level of physical activity (Table 1)}

A low level of PA was observed in $60.7 \%$ of ASCC. No differences were found in terms of PA when analyzed by group $(p=0.409)$, age $(p=0.548)$, or $\operatorname{sex}(p=0.201)$.

\section{Nutrition (Table 2)}

Among ASCC, 55.7\% always added salt to their foods, and no significant differences were observed when compared to healthy adolescents $(p=0.348)$. ASCC did not consume fruits or vegetables more frequently than healthy adolescents, although the difference was only significant for vegetable consumption $(26.2 \%$ versus $13 \%, p=0.017)$.

\section{Tobacco use (Table 3)}

No differences were observed when analyzing tobacco use by group $(p=0.151)$ or by sex $(p=0.375)$; however, there were differences in terms of age $(p<0.001)$.

Age at initiation: $14.2 \pm 2$ years old (median: $15)$ for ASCC and $13.9 \pm 2$ years old (median: 14$)$ for healthy adolescents $(p=0.637)$.

Exposure to environmental tobacco smoke was high, but there were no significant differences between both groups (77\% in the ASCC group versus $63 \%$ in the healthy adolescent group, $p=0.561$ ).

TABLE 1. Level of physical activity among adolescent survivors of childhood cancer and healthy adolescents

\begin{tabular}{lllcccccc}
\hline \multicolumn{7}{c}{ Level of physical activity } \\
\hline
\end{tabular}

ASCC: adolescent survivors of childhood cancer; N: number; $95 \%$ CI: 95\% confidence interval. 


\section{Alcohol use}

No statistical differences were observed in relation to alcohol use by group $(p=0.592)$ or sex $(p=0.734)$; however, there were differences in terms of age $(p<0.001)$. There were no cases of alcohol abuse (Table 3).
Among ASCC, 74\% started drinking alcohol after they had cancer. In relation to the first time they drank alcohol, $45 \%$ did it with friends, $43 \%$ with a relative, $8 \%$ alone, and $4 \%$ did not recall.

Age at initiation: $13.9 \pm 2$ years old (median: 14) for ASCC and $13.5 \pm 2$ years old (median: 14)

TABLE 2. Nutrition among adolescent survivors of childhood cancer and healthy adolescents: adding salt to foods. fruit consumption. vegetable consumptions

\begin{tabular}{|c|c|c|c|c|c|c|c|c|}
\hline \multicolumn{9}{|c|}{ Adding salt to foods } \\
\hline & & \multicolumn{2}{|c|}{ Always } & \multicolumn{2}{|c|}{ Rarely } & \multicolumn{2}{|c|}{ Never } & \multirow[t]{2}{*}{$\mathbf{P}$} \\
\hline & & $\mathbf{N}$ & $\%(95 \% \mathrm{CI})$ & $\mathbf{N}$ & $\%(95 \% \mathrm{CI})$ & $\mathbf{N}$ & $\%(95 \% \mathrm{CI})$ & \\
\hline \multirow[t]{2}{*}{ Group } & ASCI & 34 & $55.7(42.5-68.2)$ & 17 & $27.9(27.5-41.1)$ & 10 & $16.4(8.6-28.6)$ & 0.348 \\
\hline & Healthy adolescents & 80 & $58(49.3-66.3)$ & 27 & $19.6(13.5-27.4)$ & 31 & $22.5(16-32.5)$ & \\
\hline \multicolumn{9}{|c|}{ Consumption of fruits } \\
\hline & & \multicolumn{2}{|c|}{ No consumption } & \multicolumn{2}{|c|}{ Low } & \multicolumn{2}{|c|}{ Adequate } & $\mathbf{P}$ \\
\hline & & $\mathbf{N}$ & $\%(95 \% \mathrm{CI})$ & $\mathbf{N}$ & $\%(95 \% \mathrm{CI})$ & $\mathbf{N}$ & $\%(95 \% \mathrm{CI})$ & \\
\hline \multirow{5}{*}{ Group } & ASCC & 20 & $32.8(21.6-46.1)$ & 24 & $39.3(27.3-52.6)$ & 17 & $27.9(17.5-41.1)$ & 0.053 \\
\hline & Healthy adolescents & 24 & $17.4(11.7-25)$ & 69 & $50(41.4-58.6)$ & 45 & $32.6(25-41.2)$ & \\
\hline & & \multicolumn{6}{|c|}{ Consumption of vegetables } & \\
\hline & & \multicolumn{2}{|c|}{ No consumption } & \multicolumn{2}{|c|}{ Low } & \multicolumn{2}{|c|}{ Adequate } & $\mathbf{P}$ \\
\hline & & $\mathbf{N}$ & $\%(95 \% \mathrm{CI})$ & $\mathbf{N}$ & $\%(95 \% \mathrm{CI})$ & $\mathbf{N}$ & $\%(95 \% \mathrm{CI})$ & \\
\hline \multirow[t]{2}{*}{ Group } & ASCC & 16 & $26.2(16.1-39.3)$ & 27 & $44.3(31.8-57.5)$ & 18 & $29.5(18.9-42.7)$ & $0.017^{*}$ \\
\hline & Healthy adolescents & 18 & $13(8.1-20)$ & 89 & $64.5(55.9-72.3)$ & 31 & $22.5(16-32.5)$ & \\
\hline
\end{tabular}

* Statistically significant difference $(\mathrm{p}<0.05)$.

ASCC: adolescent survivors of childhood cancer; N: number; $95 \%$ CI: $95 \%$ confidence interval.

TABLE 3. Tobacco and alcohol use among adolescent survivors of childhood cancer and healthy adolescents

\begin{tabular}{|c|c|c|c|c|c|c|c|c|}
\hline \multicolumn{9}{|c|}{ Tobacco use } \\
\hline & & \multicolumn{2}{|c|}{ Smoker } & \multicolumn{2}{|c|}{ Former smoker } & \multicolumn{2}{|c|}{ Never smoked } & \multirow[t]{2}{*}{$\mathbf{P}$} \\
\hline & & $\mathbf{N}$ & $\%(95 \% \mathrm{CI})$ & $\mathbf{N}$ & $\%(95 \% \mathrm{CI})$ & $\mathbf{N}$ & $\%(95 \% \mathrm{CI})$ & \\
\hline \multirow[t]{2}{*}{ Group } & $\operatorname{ASCC}^{* *}$ & 3 & $4.9(1.3-14.6)$ & 15 & $24.6(14.9-37.6)$ & 43 & 70.5 (57.3-81.1) & 0.151 \\
\hline & Healthy adolescents & 15 & $10.9(6.4-17.6)$ & 21 & $15.2(9.9-22.5)$ & 102 & $73.9(65.6-80.8)$ & \\
\hline \multirow[t]{2}{*}{ Sex } & Male & 9 & $11.7(5.8-21.5)$ & 16 & $20.8(12.7-31.9)$ & 52 & $67.5(55.8-77.5)$ & 0.375 \\
\hline & Female & 9 & $7.4(3.7-14)$ & 20 & $16.4(10.5-22.4)$ & 93 & $76.2(67.5-83.2)$ & \\
\hline \multirow[t]{3}{*}{ Age } & $10-14$ years old & 0 & $0(0.1-5.3)$ & 5 & $5.8(2.2-13.6)$ & 81 & $94.2(86.4-97.8)$ & $<0.001^{*}$ \\
\hline & $15-17$ years old & 12 & $16.4(9.1-27.3)$ & 13 & $17.8(9.8-28.3)$ & 48 & $65.8(53.7-76.2)$ & \\
\hline & $\geq 18$ years old & 6 & $15(6.2-30.5)$ & 18 & $45(29.6-61.3)$ & 16 & $40(25.3-56.6)$ & \\
\hline \multicolumn{9}{|c|}{ Alcohol use } \\
\hline & & \multicolumn{2}{|c|}{ Present alcohol user } & \multicolumn{2}{|c|}{ Ever used alcohol } & \multicolumn{2}{|c|}{ Never used alcohol } & $P$ \\
\hline & & $\mathbf{N}$ & $\%(95 \%$ CI & $\mathbf{N}$ & $\%(95 \%$ CI & $\mathbf{N}$ & $\%(95 \%$ CI & \\
\hline \multirow[t]{2}{*}{ Group } & ASCC & 24 & $39.3(27.3-52.6)$ & 25 & $41(28.8-54.3)$ & 12 & $19.7(11-32.2)$ & 0.592 \\
\hline & Healthy adolescents & 44 & $31.9(24.4-40.5)$ & 64 & $46.4(37.9-55.1)$ & 30 & $21.7(15.3-29.7)$ & \\
\hline \multirow[t]{2}{*}{ Sex } & Male & 27 & $35.1(24.8-46.9)$ & 32 & $41.6(30.7-53.4)$ & 18 & $23.4(14.8-34.7)$ & 0.734 \\
\hline & Female & 41 & $33.6(25.5-42.8)$ & 57 & $46.7(37.7-55.9)$ & 24 & $19.7(13.3-28.1)$ & \\
\hline \multirow[t]{3}{*}{ Age } & $10-14$ years old & 11 & $12.8(6.9-22.2)$ & 41 & $47.7(36.9-58.7)$ & 34 & $39.5(29.3-50.6)$ & $<0.001^{*}$ \\
\hline & $15-17$ years old & 36 & $49.3(37.5-61.2)$ & 29 & $39.7(28.6-51.8)$ & 8 & $11(5.2-21.1)$ & \\
\hline & $\geq 18$ years old & 21 & $52.5(36.6-68.2)$ & 19 & $47.5(31.8-63.8)$ & 0 & $0(0.2-10.9)$ & \\
\hline
\end{tabular}

* Statistically significant difference $(\mathrm{p}<0.05)$.

** Cancer survivors who smoke or used to smoke: 15 out of 18 received treatment associated with cardiovascular risk during adulthood (anthracyclines and/or thoracic and cranial radiotherapy).

ASCC: adolescent survivors of childhood cancer; N: number; 95\% CI: 95\% confidence interval. 
for healthy adolescents; no significant differences were observed $(p=0.225)$.

Among all participants, beer was the most common starter drink (46\%), followed by cider $(22 \%)$, wine $(21 \%)$, and strong drinks $(8 \%) ; 3 \%$ did not recall their starter drink. No significant differences were observed between both groups $(p=0.762)$.

TABLE 4. CRAFFTa questionnaire for alcohol use in the past 30 days

\begin{tabular}{llccc}
\hline CRAFFT & score & $\begin{array}{c}\geq 2 \\
\mathbf{N ~ ( \% )}\end{array}$ & $\begin{array}{c}<2 \\
\mathbf{N ~ ( \% )}\end{array}$ & $\mathbf{P}$ \\
\hline \multirow{2}{*}{ Group } & Survivors & $3(25)$ & $21(37.5)$ & 0.319 \\
& Healthy controls & $9(75)$ & $35(62.5)$ & \\
Age & Up to 14 years old & $0(0)$ & $11(19.6)$ & $0.045^{*}$ \\
& 15 to 17 years old & $6(50)$ & $30(53.6)$ & \\
\multirow{2}{*}{ Sex } & 18 or more years old $6(50)$ & $15(26.8)$ & \\
& Male & $7(58.3)$ & $20(35.7)$ & 0.197 \\
& Female & $5(41.7)$ & $36(64.3)$ & \\
\hline
\end{tabular}

N: number; \%: percentage; $95 \%$ CI: 95\% confidence interval.

${ }^{a}$ CRAFFT. acronym for the questionnaire components: Car (driving after using alcohol). Relax (using alcohol to relax or feel better). Alone (using alcohol while you are alone). Forget (not recalling what happened after using alcohol). Friends/ Family (having friends or family members who noted that you drink too much). Trouble (getting into trouble while under the influence of alcohol). Each positive answer scores one point; a score of 2 or higher indicates alcohol abuse. (Validity of the CRAFFT Substance Abuse Screening Test among Adolescent Clinic Patients. Arch Pediatr Adolesc Med 2002;156: 607-614).
In addition, $34 \%$ of participants had drunk alcohol in the past 30 days (24 in the ASCC group and 44 in the healthy adolescent group). After administering the CRAFFT questionnaire to these participants (Table 4), differences were not significant by group $(p=0.319)$ or sex $(p=0.197)$, but they were significant in terms of age $(p=0.045)$. When counting the number of alcoholic drinks on one occasion (Table 5), ASCC had a higher OEAU in relation to strong drinks $(p=0.049)$. There were no significant differences between groups regarding the time of the week when OEAU took place (weekdays, weekends, or both).

\section{DISCUSSION}

Survivors of childhood cancer have a high risk of suffering from cardiometabolic conditions as adults as a result of cancer treatment. In spite of being a vulnerable population, these survivors display risky behaviors similar to the general population. Although tobacco and alcohol use is generally lower than in the general population, ${ }^{12-15,21}$ there are subsets who frequently abuse alcohol. ${ }^{14,22-24}$ Pediatricians are in an exceptional position to promote healthy habits and perform periodic check-ups for an early screening of cardiometabolic complications among ASCC.

Salt consumption was higher among ASCC when compared to the national average $(25 \%$

TABLE 5. Occasional excessive alcohol use in the past 30 days

\begin{tabular}{|c|c|c|c|c|c|c|}
\hline \multirow{3}{*}{$\begin{array}{l}\text { Occasional excessive } \\
\text { alcohol use }\end{array}$} & & \multicolumn{4}{|c|}{ Group } & \multirow[t]{3}{*}{$\mathbf{P}$} \\
\hline & & \multicolumn{2}{|c|}{$\operatorname{ASCC}(n=24)$} & \multicolumn{2}{|c|}{ Healthy adolescents $(n=44)$} & \\
\hline & & $\mathbf{N}$ & $\%(95 \% \mathrm{CI})$ & $\mathbf{N}$ & $\%(95 \% \mathrm{CI})$ & \\
\hline \multirow[t]{2}{*}{ OEAU of beer } & Yes & 3 & $12.5(3.3-33.5)$ & 3 & $6.8(1.8-19.7)$ & 0.658 \\
\hline & No & 21 & $87.5(66.5-96.7)$ & 41 & $93.2(80.3-98.2)$ & \\
\hline \multirow[t]{2}{*}{ OEAU of wine } & Yes & 0 & $0(0.4-17.2)$ & 1 & $2.3(0.1-13.5)$ & 0.585 \\
\hline & No & 24 & $100(82.8-99.6)$ & 43 & $97.7(86.5-99.9)$ & \\
\hline \multirow[t]{2}{*}{ OEAU of a strong } & Yes & 4 & $16.7(5.5-38.2)$ & 1 & $2.3(0.1-13.5)$ & $0.049^{*}$ \\
\hline & No & 20 & $83.3(61.8-94.5)$ & 43 & $97.7(86.5-99.9)$ & \\
\hline \multirow[t]{2}{*}{ OEAU on weekdays ${ }^{b}$} & Yes & 1 & $4.2(0.2-23.2)$ & 2 & $4.5(0.8-16.6)$ & 0.736 \\
\hline & No & 23 & $95.8(76.8-99.8)$ & 42 & $95.5(83.4-99.2)$ & \\
\hline \multirow[t]{2}{*}{ OEAU on weekends ${ }^{c}$} & Yes & 9 & $37.5(19.6-59.2)$ & 11 & $25(13.7-40.6)$ & 0.210 \\
\hline & No & 15 & $62.5(40.8-80.4)$ & 33 & $75(59.4-86.3)$ & \\
\hline \multirow[t]{2}{*}{ Total combined OEAU ${ }^{\mathrm{d}}$} & Yes & 3 & $12.5(3.3-33.5)$ & 2 & $4.5(0.8-16.6)$ & 0.233 \\
\hline & No & 21 & $87.5(66.5-96.7)$ & 42 & 95.5 (83.4-99.2) & \\
\hline
\end{tabular}

\footnotetext{
* Statistically significant difference $(\mathrm{p}<0.05)$.
}

$\mathrm{N}$ : number; $95 \% \mathrm{CI}$ : 95\% confidence interval; OEAU: occasional excessive alcohol use.

a Strong drink: high grade beverage (whisky. vodka. gin. fernet).

b Weekdays: Monday through Thursday.

c Weekend: Friday through Sunday.

d Total combined: aggregated occasional excessive alcohol use on weekdays and weekends. 
in 2009). ${ }^{25}$ Their level of physical activity was below the current recommendations. ${ }^{26} \mathrm{~A}$ low level of physical activity was observed in $60 \%$ of survivors. As seen in the general population, childhood cancer survivors do not take part in healthy activities, and few of them have a balanced diet and do regular exercise. ${ }^{27}$

ASCC, especially those who had leukemia, were significantly more obese and had a larger WC, indicative of increased abdominal fat. Obesity is common following acute lymphoblastic leukemia. Possible causes of obesity include female gender, genetic factors, steroid exposure, hypothalamic damage due to cranial radiotherapy in the first decade of life, and a sedentary lifestyle. . $^{928-30}$

Since a sedentary lifestyle is the only modifiable factor, some authors state that it is critical to promote lifestyles that prevent obesity and its complications. ${ }^{28}$

ASCC showed a high exposure to environmental tobacco smoke, and almost one third used tobacco. A longitudinal study with 119 non-smoker ASCC showed that $22.7 \%$ were smokers in the 10-year follow-up assessment; considering smoking was the strongest predictor of future tobacco use. ${ }^{11}$ Having received highly toxic cardiopulmonary therapy does not appear to modify smoking prevalence. ${ }^{13}$

Alcohol use was higher than tobacco use in both groups. No significant differences were found in alcohol or tobacco use by group or age; however, differences were significant by age. There was a marked increase in use among adolescents as of 15 years old. In half of the cases, beer was the starter drink of choice. Alcohol use occurred mainly on weekends. Such alcohol use pattern is consistent with that described by the Argentine Secretariat of Planning for the Prevention of Drug Addiction and Action against Drug Trafficking (Secretaría de Programación para la Prevención de la Drogadicción y la Lucha contra el Narcotráfico, SEDRONAR). ${ }^{31}$

Among ASCC, 74\% started using alcohol after they had cancer, and $43 \%$ of these did it with a relative.

It should be noted that, in certain aspects, adolescent health is similar to that of adults. In Argentina, between 2005 and 2009, there was a significant increase in physical inactivity, unhealthy nutrition and obesity in the general population..$^{25}$ In the same period, smoking was reduced. ${ }^{25,31}$

Oeffinger describes childhood cancer survivors as a group that differs from the traditional chronic condition model in which patients live with their primary condition and symptoms throughout their lives. In contrast, cancer survivors usually live their adolescence with no sequelae and, over the years, develop one or more health conditions different from their original disease as a result of toxicity related to cancer treatment, which mainly involves the nervous, cardiovascular and endocrine systems. In the case of cardiovascular disease and metabolic syndrome, cancer treatment toxicity is a synergistic action that combines with congenital risk factors and a sedentary lifestyle. ${ }^{32}$

\section{Limitations}

First and foremost, it was not possible to reach the sample size in the time allowed by the research fellowship, mostly because medical record data were out of date, making it impossible to contact all ASCC. The smaller sample size may point some of the differences as "not significant;" however, this does not render results invalid when differences were significant. Secondly, the proportion of males and females was different in each group, and this may have led to not finding differences by sex, as observed in other studies. In the third place, data were reported by adolescents themselves, and some behaviors may have been exaggerated or minimized; however, data were similar to those of other studies. Finally, the study did not include a longitudinal comparison that would have allowed to know whether differences remain over time.

Other equally important risk factors (drug use, skin care, sexual intercourse, academic achievement, and emotional factors) were not assessed in this study.

To sum up, experimentation behaviors, which imply using the body as a trial field, are typical of adolescence. Many of such behaviors become habits and add to the already vulnerable health status of ASCC, resulting in a detrimental lifestyle, for example, a sedentary lifestyle, an unhealthy nutrition, tobacco and alcohol use, and all such habits become risk factors for cardiometabolic conditions. Risk-based periodic medical check-ups are necessary to improve long-term care in this growing population. Longitudinal studies are required to assess risk factors independently.

\section{CONCLUSIONS}

ASCC had a higher risk for obesity and a larger WC; in addition, they consumed less vegetables than healthy adolescents. The prevalence of the 
remaining factors for cardiometabolic risk was similar.

\section{Acknowledgments}

We would like to thank the Teaching and Research Committee, the Ethics Committee, the Department of Adolescence and the Service of Hematooncology of Hospital de Niños Pedro de Elizalde. Also, to Fernando Ferrero, M.D., for making a critical review of the article.

\section{REFERENCES}

1. Leisenring WM, Mertens AC, Armstrong GT, Stovall MA, et al. Pediatric cancer survivorship research: experience of the Childhood Cancer Survivor Study. J Clin Oncol 2009;27(14):2319-27.

2. Geenen MM, Cardous-Ubbink MC, Kreme LC, van den Bos C, et al. Medical assessment of adverse health outcomes in long-term survivors of childhood cancer. JAMA 2007;297(24):2705-15.

3. Oeffinger KC, Mertens AC, Sklar CA, Kawashima T, et al. Chronic health conditions in adult survivors of childhood cancer. N Engl J Med 2006;355(15):1572-82.

4. Reulen RC, Winter DL, Frobisher C, Lancashire ER, et al. Long-term cause-specific mortality among survivors of childhood cancer. JAMA 2010;304(2):172-9.

5. Kavey RE, Allada V, Daniels SR, Hayman LL, et al. Cardiovascular risk reduction in high- risk pediatric patients: a scientific statement from the American Heart Association Expert Panel on Population and Prevention Science; the Councils on Cardiovascular Disease in the Young, Epidemiology and Prevention, Nutrition, Physical Activity and Metabolism, High Blood Pressure Research, Cardiovascular Nursing, and the Kidney in Heart Disease; and the Interdisciplinary Working Group on Quality of Care and Outcomes Research: endorsed by the American Academy of Pediatrics. Circulation 2006;114(24):2710-38.

6. Siviero-Miachon AA, Spinola-Castro AM, Guerra-Junior G. Detection of metabolic syndrome features among childhood cancer survivors: a target to prevent disease. Vasc Health Risk Manag 2008;4(4):825-36.

7. Lipshultz SE, Landy DC, Lopez-Mitnik G, Lipsitz SR, et al. Cardiovascular status of childhood cancer survivors exposed and unexposed to cardiotoxic therapy. JClin Oncol 2012;30(10):1050-7.

8. Küpeli S, Hazirolan T, Varan A, Akata D, et al. Evaluation of coronary artery disease by computed tomography angiography in patients treated for childhood Hodgkin's lymphoma. J Clin Oncol 2010;28(6):1025-30.

9. Green DM, Cox CL, Zhu L, Krull KR, et al. Risk factors for obesity in adult survivors of childhood cancer: a report from the Childhood Cancer Survivor Study. J Clin Oncol 2012;30(3):246-55.

10. Ness KK, Leisenring WM, Huang S, Hudson MM, et al. Predictors of inactive lifestyle among adult survivors of childhood cancer: a report from the Childhood Cancer Survivor Study. Cancer 2009;115(9):1984-94.

11. Klosky JL, Tyc VL, Hum A, Lensing S, et al. Establishing the predictive validity of intentions to smoke among preadolescents and adolescents surviving cancer. J Clin Oncol 2010;28(3):431-6.

12. Nathan PC, Ford JS, Henderson TO, Hudson MM, et al. Health behaviors, medical care, and interventions to promote healthy living in the Childhood Cancer Survivor Study cohort. J Clin Oncol 2009;27(14):2363-73.

13. Larcombe I, Mott M, Hunt L. Lifestyle behaviours of young adult survivors of childhood cancer. Br J Cancer 2002;87(11):1204-9.

14. Clarke SA, Eiser C. Health behaviours in childhood cancer survivors: a systematic review. Eur J Cancer 2007;43(9): 1373-84.

15. Hudson MM, Findlay S. Health-risk behaviours and health promotion in adolescent and young adult cancer survivors. Cancer 2006;107(7 Suppl):1695-701.

16. Nathan PC, Greenberg ML, Ness KK, Hudson MM, et al. Medical care in long-term survivors of childhood cancer: a report from the Childhood Cancer Survivor Study. JClin Oncol 2008;26(27):4401-9.

17. Fundación Kaleidos, Instituto Nacional delCáncer. Registro Oncopediátrico Hospitalario Argentino. Resultados 20002008. Buenos Aires, 2010.

18. Abriata MG, Moreno F. Cáncer en la población de menores de 15 años en Argentina. Rev Argent Salud Publica 2010;1(3):42-5.

19. Sociedad Argentina de Pediatría. Curvas de crecimiento y referencias de tensión arterial para niños, niñas y adolescentes. Buenos Aires. Available at: http:/ / www.sap. org.ar/prof- percentilos.php. [Accessed on: May 10, 2012].

20. Comité Nacional de Nutrición. Guías de práctica clínica para la prevención, el diagnóstico y el tratamiento de la obesidad. Arch Argent Pediatr 2011;109(3):256-66.

21. Rebholz CE, Rueegg CS, Michel G, Ammann RA, et al. Clustering of health behaviours in adult survivors of childhood cancer and the general population. Br J Cancer 2012;107(2):234-42.

22. Lown EA, Goldsby R, Mertens AC, Greenfield T, et al. Alcohol consumption patterns and risk factors among childhood cancer survivors compared to siblings and general population peers. Addiction 2008;103(7):1139-48.

23. Klosky JL, Howell CR, Li Z, Foster RH, et al. Risky health behavior among adolescents in the Childhood Cancer Survivor Study Cohort. J Pediatr Psychol 2012;37(6):634-46.

24. Frobisher C, Lancashire ER, Reulen RC, Winter DL, et al. Extent of alcohol consumption among adult survivors of childhood cancer: The British Childhood Cancer Survivor Study. Cancer Epidemiol Biomarkers Prev 2010;19(5):1174-84.

25. Ferrante D, Linetzky B, Konfino J, King A, et al. Encuesta nacional de factores de riesgo 2009: evolución de la epidemia de enfermedades crónicas no transmisibles en Argentina: estudio de corte transversal. Rev Argent Salud Publica 2011;2(6):34-41.

26. Capítulo 4, Niveles de actividad física para la salud recomendados a la población. En: Organización Mundial de la Salud. Recomendaciones mundiales sobre actividad física para la salud. Ginebra; 2010. Págs.15-31.

27. Stolley MR, RestrepoJ, Sharp LK. Diet and physical activity in childhood cancer survivors: a review of the literature. Ann Behav Med 2010;39(3):232-49.

28. Meacham LR, Gurney JG, Mertens AC, Ness KK, et al. Body mass index in long-term adult survivors of childhood cancer: a report of the Childhood Cancer Survivor Study. Cancer 2005;103(8):1730-9.

29. Garmey EG, Liu Q, Sklar CA, Meacham LR, et al. Longitudinal changes in obesity and body mass index among adult survivors of childhood acute lymphoblastic leukemia: a report from the Childhood Cancer Survivor Study. J Clin Oncol 2008;26(28):4639-45.

30. Argentina. SEDRONAR. Estudio Nacional sobre consumo en estudiantes de enseñanza media. Informe preliminar 2011: Dirección Nacional del Observatorio Argentino de Drogas. Availableathttp:/ / proyectoenfoques.com.ar/wpcontent/uploads/1370448943.pdf. [Accessed on: October 21, 2014].

31. Oeffinger KC, Robison LL. Childhood cancer survivors, late effects, and a new model for understanding survivorship. JAMA 2007;297(24):2762-4. 